\title{
A narrative review of surgical management of lung cancer involving the chest wall: oncologic results
}

\author{
Michael Lanuti \\ Division of Thoracic Surgery, Harvard Medical School, Massachusetts General Hospital, Boston, MA, USA \\ Correspondence to: Michael Lanuti, MD. Director of Thoracic Oncology, Division of Thoracic Surgery, Associate Professor of Surgery, Harvard \\ Medical School, Massachusetts General Hospital, 55 Fruit Street, Blake 1570, Boston, MA 02114, USA. Email: MLanuti@mgh.harvard.edu.
}

\begin{abstract}
The prevalence of chest wall invasion by non-small cell lung cancer (NSCLC) is $<10 \%$ in published surgical series; however, its presence can greatly influence surgical management and invoke multimodality therapy. Randomized trials investigating the role of multi-modality therapy for lung cancer with chest wall invasion are few and are primarily limited to the management of superior sulcus tumors. The role of radiation or chemotherapy around the complete resection of lung cancer invading the chest wall, excluding the superior sulcus of the chest, has not been effectively evaluated in a randomized prospective study. Survival of patients with lung cancer invading the chest wall is highly dependent on the extent of lymph node involvement and the completeness of en-bloc resection. When performing chest wall resection, $\geq 1 \mathrm{~cm}$ margin in all directions is generally accepted. Invasive mediastinal staging should be a mandatory part of the metastatic survey of any patient harboring NSCLC with radiographic or clinical chest wall invasion. Surgeons should strive for complete resection and implement reconstruction techniques that are appropriate for chest wall location. Chest wall defects $<5 \mathrm{~cm}$ can often be managed without reconstruction. In carefully selected patients, 5-year survival in excess of $50 \%$ can be achieved in patients harboring T3N0 disease. Offering en-bloc resection of lung cancer invading chest wall to patients with T3N1 or T3N2 disease is controversial.
\end{abstract}

Keywords: Lung cancer; chest wall invasion; en-bloc resection

Received: 04 August 2020; Accepted: 04 September 2020; Published: 25 May 2021.

doi: 10.21037/ccts-2019-cwt-09

View this article at: http://dx.doi.org/10.21037/ccts-2019-cwt-09

\section{Introduction}

Chest wall invasion by non-small cell lung cancer (NSCLC) is not a contra-indication to curative treatment. The prevalence of chest wall invasion by NSCLC is $<10 \%$ in published surgical series. These tumors are given a $\mathrm{T} 3$ or T4 designation in the $8^{\text {th }}$ edition TNM staging depending on chest wall or vertebral body invasion (1). Long-term survival in patients harboring this locally aggressive neoplasm has been associated with complete (R0) resection and node negative disease (2-4). Preoperative radiation and en-bloc resection was promulgated in the 1950s by Shaw and Paulson for tumors approaching the thoracic inlet (5). This strategy was the historic standard of care until the 1990s when neoadjuvant chemotherapy and radiation were explored in clinical series. Since that time, induction therapy strategies have been primarily elucidated in Pancoast tumors (6-8) where efficacy in chest wall invasion outside of the superior sulcus is supported by a sparse literature comprised of single institution series.

Successful chest wall resection in continuity with a lung cancer was first published in 1947 by Coleman, where threequarter of patients undergoing pneumonectomy experienced freedom from disease at 5 mo-6 years after the operation (9). In subsequent decades, there have been retrospective series from single institutions that have attempted to address prognostic factors $(7,10-13)$. Advances in the technical approach to removing superior sulcus tumors were described by Dartevelle and colleagues in 1993 (14). The field appeared to move forward again in the prospective evaluation of patients with Pancoast tumors when results 
of a multi-institutional phase II trial (Southwest Oncology Group 9416) was published in 2007 by Rusch and trial participants (15). This study involved 76 surgeons from all North American cooperative groups to enroll 110 patients with T3-4 disease who received two cycles of cisplatin and etoposide concurrently with 45 Gy radiation. This cohort achieved 54\% 5-year survival after complete resection. Pathologic complete response or minimal microscopic disease was identified in $56 \%$ of resected specimens. This was corroborated in a phase II Japanese Clinical Oncology Group Trial 9806 where patients were treated with induction chemoradiotherapy followed by en-bloc resection achieving 56\%, 5-year overall survival (16). The Thoracic Surgery Division at Toronto General Hospital reported on a retrospective series of 48 patients with NSCLC invading the superior sulcus or spine using the SWOG 9416 treatment strategy where a pathologic or near pathologic complete response was seen in $50 \%$ of patients (17). Employing this paradigm to lung cancers invading the chest wall outside of the superior sulcus was explored by a Japanese Lung Study Group in a phase II trial of chemotherapy (two cycles of cisplatin + vinorelbine) concurrent with radiotherapy (40 Gy) followed by surgery (18). Although the study included some superior sulcus tumors, a pathologic complete response was seen in 13 (26\%) patients. Five-year overall survival was $63 \%$ with a median follow up of 42 months. The authors observed a significant difference in the survival rate between patients with a pathologic complete response and those with residual tumor $(\mathrm{P}=0.039)$. This manuscript attempts to provide a succinct review of the management of chest wall invasion by NSCLC. I present the following article in accordance with the Narrative Review reporting checklist (available at https://ccts.amegroups.com/article/ view/10.21037/ccts-2019-cwt-09/rc).

\section{Methods}

PubMed was searched using the keywords "lung cancer, non-small cell lung cancer and chest wall invasion" from 1985 to May 2020. Systematic reviews, randomized clinical trials, retrospective cohort and cross-sectional studies written in English were evaluated for inclusion. Guideline recommendations from the National Cancer Care Network were also included and referenced.

\section{Clinical presentation}

Chest wall pain is the most common clinical presentation of chest wall invasion in patients diagnosed with primary bronchogenic carcinoma. Although localized chest pain is highly predictive of direct chest wall invasion, the absence of pain does not exclude the possibility. In one study, $7.5 \%$ of patients with tumor extending to the periosteum did not have pain (19). Another important aspect in the early management of a lung tumor involving chest wall is histologic confirmation of the disease. Differentiating lung cancer from a primary tumor of the chest wall extending into lung will greatly influence the treatment plan. Given the complexity of these locally aggressive neoplasms, patients should routinely be evaluated by a multi-disciplinary team including neurosurgery, orthopedic spine surgery, and or plastic surgery when appropriate. A bone scan or PET scan is not very useful in determining chest wall invasion. MRI is more accurate than CT scanning in depicting chest wall invasion, especially in the superior sulcus region.

\section{Principles of surgical treatment}

Complete and accurate staging is paramount, particularly in patients harboring lung cancer invading or abutting any part of the chest wall. Patients should undergo diagnostic quality CT chest, PET with attenuation correction CT and brain MRI to rule out intracranial disease given the more aggressive phenotype of these tumors. Chest or spine MRI can be obtained to delineate encroachment of tumor into the vertebral foramen, or brachial plexus and subclavian vessels in the case of superior sulcus tumors. MRI with respiratory gating has a distinct advantage of demonstrating independent movements of lung and chest wall, therefore improving the sensitivity of tumor invasion into parietal pleura or diaphragm (20). If complete en-bloc resection is achievable, MRI will not necessarily change the surgical management of tumors located outside of the superior sulcus. If spinal elements are involved, consultation with a spine surgeon will be necessary in planning en-bloc resection. Flexible bronchoscopy should not be overlooked since a subgroup of these patients will present with endobronchial disease that may influence the operative strategy.

Pathologic mediastinal nodal staging is critical to improve patient selection for curative multimodality therapy. This can be achieved by endobronchial ultrasound (EBUS), a combination of EBUS and esophageal ultrasound, cervical mediastinoscopy, anterior mediastinotomy (Chamberlain procedure) or video assisted thoracoscopy. The presence of N2 disease has been reproducibly associated with worse outcome in patients harboring lung cancer with chest wall 


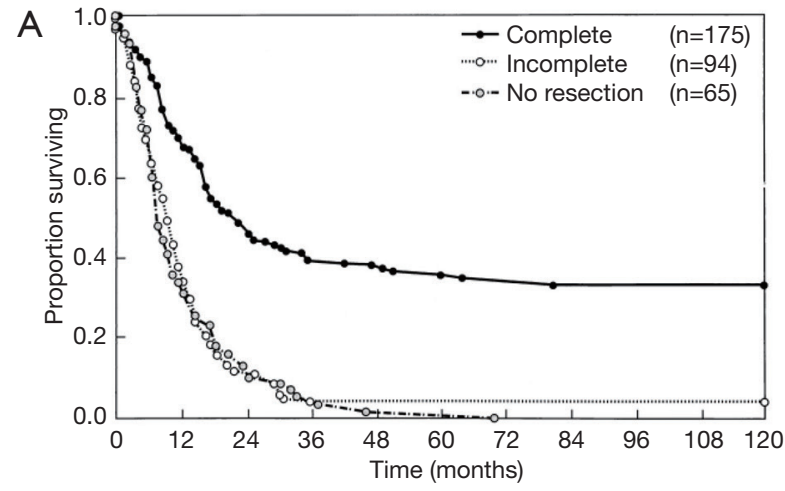

Completeness of resection

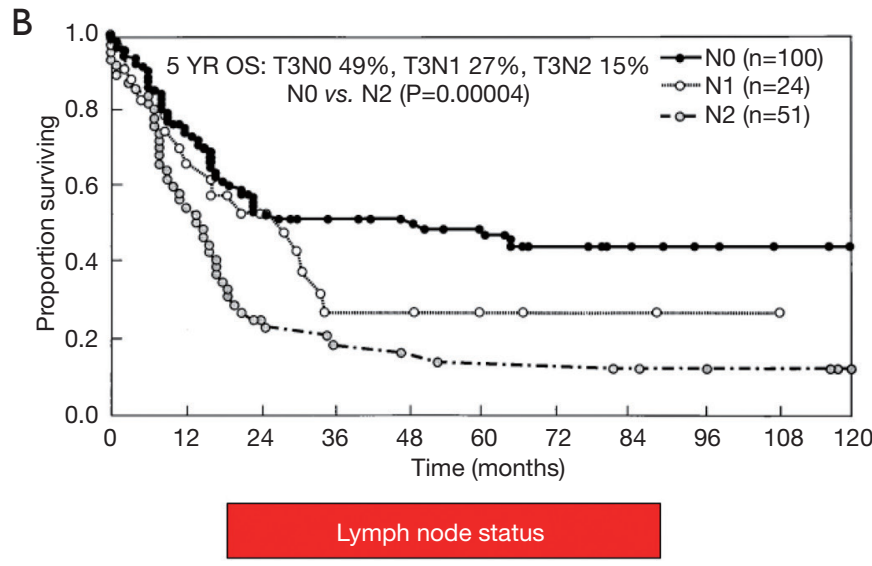

Figure 1 Results of retrospective series of 334 patients undergoing exploration for lung cancer involving the chest wall (10). (A) Overall survival after complete, incomplete or no resection in T3 tumors; (B) overall survival by nodal involvement (N0, N1, N2) in patients with completely resected $\mathrm{T} 3$ tumors.

invasion. Facciolo and colleagues reported an 18\% 5-year overall survival for T3N2 disease compared to $61 \%$ for T3N0 in 104 patients treated with en-bloc resection of lung neoplasms involving the chest wall (19). In a series of 201 patients treated with en-bloc resection, Magdeleinat and colleagues (4) reported 21\% 5-year survival in patients with T3N2 disease. No survival difference was noted between patients with N1 or N2 disease. Downey and colleagues reported on 334 patients who underwent exploration of tumors with chest wall invasion and observed superior survival with complete (R0) resection and a 5 -year overall survival of $49 \%$ for T3N0 tumors compared to $27 \%$ and $15 \%$ for T3N1 and T3N2 tumors, respectively (Figure 1) (10). If en-bloc resection is being considered, adequate cardiopulmonary reserve must be confirmed by pulmonary function tests and assessment of cardiac function. When performing chest wall resection, $\geq 1 \mathrm{~cm}$ margin in all directions is generally accepted; however, some would advocate for obtaining a margin of one intact rib above and below the tumor with a $3-4 \mathrm{~cm}$ lateral margin (19). Factors that influence the surgical approach to lung cancer invading the chest wall include body habitus, tumor location and a history of previous radiation. Reconstruction with prosthetic material is predicated on size and site (anterior, posterior or lateral) of the chest wall defect. Anterior chest wall defects are often reconstructed with rigid fixation given the proximity of the heart and vital structures. The anterior location can be particularly challenging for tumors that involve sternum along the sternoclavicular joints or multiple anterior ribs. Reconstruction options in this location require rigid fixation due to vulnerability of the underlying structures and the potential for paradoxical movement of the chest wall which can be functionally and cosmetically undesirable. Materials that have been historically considered include polypropylene (Marlex) mesh sandwiched around methyl methacrylate resin or polytetrafluoroethylene (PTFE) mesh of 2-mm thickness (Figure 2). Novel methods for rigid chest wall reconstruction include titanium ribs (21), a "rib-like" method using an aluminum cast with mesh and acrylic or methyl methacrylate resins (22), cryopreserved allografts fixed with titanium screws and plates (23), titanium micromesh sandwiched between a layer of polyethylene mesh (24), or a tailored carbon fiber prosthesis with jointlike properties (25). All of these methods can be associated with prosthesis migration, dislocation or infection. The ideal rigid replacement for chest wall defects should achieve chest wall stability, resist infection or prosthesis migration, have potential for tissue ingrowth, and provide a good functional and cosmetic result. In general, chest wall defects $<5 \mathrm{~cm}$ can be managed without reconstruction. Posterior chest wall defects under the scapula do not routinely require reconstruction unless the geometry will cause scapular tip entrapment. Lateral chest wall defects that are over $5 \mathrm{~cm}$ in size can be constructed with PTFE alone (if rigid fixation is not necessary).

Some area of controversy surrounds extrapleural dissection versus en-bloc chest wall resection when tumor invades the parietal pleura. This really depends on the presence of bone invasion. The assessment of a tumorfree plane is subjective where many surgeons perform 

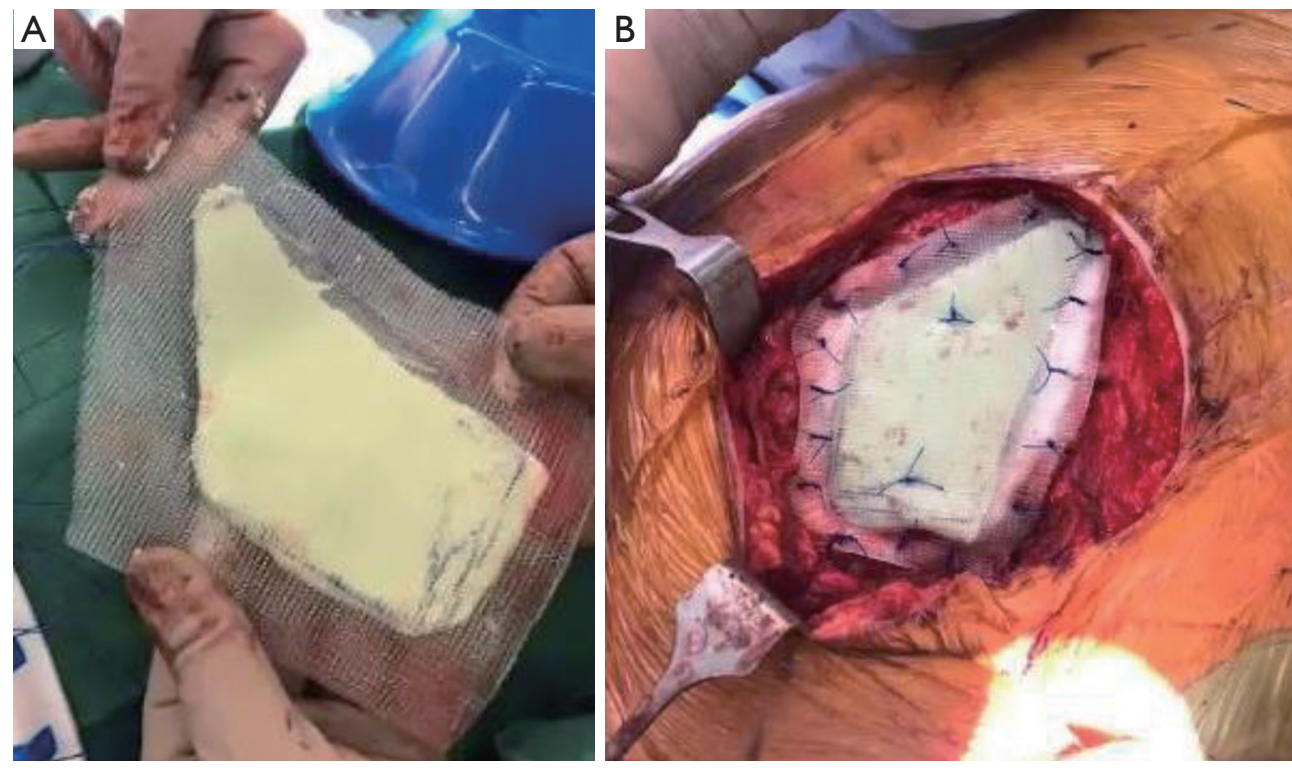

Figure 2 Fabrication of rigid chest wall reconstruction with polypropylene (Marlex) mesh sandwiched around methyl methacrylate resin (A) and sutured to an anterior chest wall defect with proline suture (B).

extrapleural dissection until encountering macroscopic invasion. It should be noted that frozen section specimens composed of soft tissue with bone do not routinely help guide the surgeon intraoperatively, since bone specimens need to be decalcified (which can take nearly a week to achieve). Thoracic surgeons should proceed with caution and use an extrapleural dissection plane only in the presence of filmy adhesions with a discernible plane between visceral and parietal pleura. A few published series address this issue. Piehler reported a $75 \% 5$-year survival with en-bloc resection in contrast to $28 \%$ after an extrapleural resection (2). Albertucci and coauthors reported a $37.5 \%$ rate of local recurrence $v s .9 .5 \%$ in patients undergoing extrapleural resection compared to $e n-b l o c$ chest wall resection, respectively (26).

\section{Role of surgery followed by adjuvant therapy}

Since 1990, published literature is sparse on the specific role of radiation in patients with lung cancer and chest wall invasion. Although one may extrapolate from the success of concurrent radiation on superior sulcus tumors, the added benefit of radiation in completely resectable tumors remains unclear. One of the few studies that addressed this issue was published in 1982 from the Toronto group reporting outcomes on 35 patients with completely resected lung cancers invading the chest wall (27). In those patients who received radiation ( $\mathrm{N}=13,8$ postoperatively), 56\% 5-year survival was reported compared to $30 \%$ in non-radiated patients. Overall survival in the entire cohort was $38 \%$ at 5 years. In contrast, postoperative radiation was employed in $74 \%(139 / 201)$ of patients in a larger retrospective population treated with en-bloc chest wall resection for invasive lung cancer, where there was no apparent benefit in survival (4). Overall survival in the entire cohort was $21 \%$ at 5 years. Survival in this study was influenced by age $>65$, depth of chest wall invasion, completeness of resection and nodal involvement. A larger retrospective study that combined the experience of 3 centers in France ( $N=309$ patients treated with en-bloc resection) showed no benefit to adjuvant radiation in T3N0 patients who underwent en-bloc resection (13). Nonetheless, adjuvant radiation in patients with resected $\mathrm{T} 3 \mathrm{~N} 1$ or $\mathrm{T} 3 \mathrm{~N} 2$ (stage IIIA) disease did experience increased survival.

\section{Role of multimodality therapy}

Excluding lung cancers that invade the apical chest wall or thoracic inlet, studies evaluating multi-modality therapy for lung cancers invading other parts of the chest wall are few. Overall survival for T3N0 NSCLC is $53 \%$ in the $8^{\text {th }}$ edition TNM staging. The T3 designation in the $8^{\text {th }}$ edition TNM staging also includes tumors $>5$ but $<7 \mathrm{~cm}$ with no chest wall invasion. If a surgeon can achieve a complete $e n-b l o c$ 
Table 1 Outcomes of larger retrospective studies since 1999 in NSCLC patients treated with en-bloc chest wall resection

\begin{tabular}{|c|c|c|c|c|c|}
\hline Study & $\mathrm{N}$ & Mortality & 5-year survival & Local recurrence & Distant recurrence \\
\hline Chapelier et al. (30) & 100 & $4 \%$ & $18 \%$ & $13 \%$ & $45 \%$ \\
\hline Magdeleinat et al. (4) & 201 & $7 \%$ & $21 \%$ & $10 \%$ & $8 \%$ \\
\hline Facciolo et al. (19) & 104 & $0 \%$ & $61 \%$ & $3 \%$ & $22 \%$ \\
\hline Deslauriers et al. (31) & 125 & $6 \%$ & $31 \%$ & $43 \%$ & $50 \%$ \\
\hline Jones et al. (32) & 100 & $2 \%$ & $45 \%$ & $12 \%$ & $18 \%$ \\
\hline
\end{tabular}

*, The survival and recurrence are reported for R0 resection ( $N=175)$. NSCLC, non-small cell lung cancer; NR, not reported.

resection, why employ more modalities for cure. Some have put forth the argument that induction therapy may increase the rate of resectability, influence a complete pathologic response (which has been associated with improved survival), and control micrometastases. Kawaguchi et al. studied lung cancer invading the chest wall prospectively in 51 patients with T3N0, T3N1 who received two cycles of chemotherapy (cisplatin/vinorelbine) concurrently with 40 Gy radiation followed by resection (28). Some superior sulcus tumors were included in this multi-institutional study and PET staging was not mandatory. Recurrence was observed in $25 \%$ of the patients, where loco-regional recurrence was $10 \%$. The median follow-up was only 16 months with a 2 -year overall survival of $85 \%$. Complete pathologic response was identified in only $25 \%$ of patients perhaps due to the lower radiation dose.

The 2020 National Comprehensive Care Network (NCCN) guideline for NSCLC involving the chest wall recommends surgery as the primary treatment modality for patients with T3N0-1 or T4N0-1 disease, reserving adjuvant chemotherapy \pm radiation for incomplete (R1 or R2) resection (29). Preoperative chemotherapy or concurrent chemoradiotherapy can also be considered in carefully selected patients with similar disease that is amenable to complete resection. Definitive concurrent chemoradiotherapy is recommended in patients with lung cancer invading chest wall with pathologically proven $\mathrm{N} 2$ disease.

\section{Prognostic factors}

Review of survival and recurrence in large retrospective series (Table 1) evaluating en-bloc resection of chest wall invasive non-small cell lung reveals a $32 \%$ average 5 -year overall survival with a high rate of locoregional and systemic recurrence. Factors that predict poor outcome in this patient population have not really changed over the past 30 years. Incomplete resection remains the most reproducible independent predictor of poor survival in all published series. The absence of lymph node metastases (T3N0 disease) consistently has superior outcome across published series reaching as high as $~ 70 \% 5$-year survival (19). The presence of N1 or N2 disease portends worse survival in several published series reporting on the surgical management of chest wall invasion of lung cancer $(2,13,30,33)$. The Memorial Sloan-Kettering Group reported 49\% 5-year survival in completely resected T3N0 disease compared to $27 \%$ in $\mathrm{T} 3 \mathrm{~N} 1$ disease and $15 \%$ in T3N2 disease $(\mathrm{P}<0.0003)(10)$. In a multivariate analysis of a more contemporary study (32) examining outcomes in 100 patients treated for NSCLC invading the chest wall (excluding superior sulcus tumors), no radiographic response to induction therapy was the strongest predictor of worse overall survival (OR $=7.35)$ where $73 \%$ of the patients underwent induction therapy. Pathologic N2 disease was associated with worse disease-free survival with $\mathrm{OR}=3.12$. Some studies showed no survival advantage between N1 vs. N2 disease (4,34). The depth of chest wall invasion into parietal pleura has not consistently been associated with worse outcome. Lastly, two studies $(13,30)$ reported that the extent of chest wall resection (assessed by the number of ribs removed and not the tumor free margin) was a predictor of survival. This prognostic factor is likely a surrogate for tumor size.

\section{Summary}

Although surgical techniques and approaches to lung cancer invading the chest wall have incrementally evolved over the 
past decades, a curative strategy for this disease is predicated on the ability to achieve a complete (R0) en-bloc resection in the face of limited to no lymph node involvement. N2 disease remains a relative contraindication to surgical resection except in carefully selected patients with exceptional performance status where expected outcomes will not exceed $15-21 \%$ 5-year survival. Despite evidence that supports induction chemoradiotherapy for superior sulcus tumors, there is little evidence to support adjuvant chemotherapy or radiation around completely resected T3N0 disease. Induction chemoradiotherapy for chest wall invasion of NSCLC that excludes the superior sulcus has not been vetted in a randomized controlled trial but some institutions have been exploring this option by extrapolating from the success of multi-modality treatment of Pancoast tumors (32). Although many studies suggest that T3N1 disease has worse outcome compared to N0 disease, most surgeons will offer en-bloc resection of chest wall and lung since the hilar (N1) disease can be encompassed in a complete resection. Chemotherapy should strongly be considered in this patient population, but timing of delivery (preoperative $v s$. postoperative) remains undetermined. Surgeons need to be well versed in the technical aspects of these operations including understanding the merits and limitations of all available reconstructive strategies.

\section{Acknowledgments}

Funding: None.

\section{Footnote}

Provenance and Peer Review: This article was commissioned by the Guest Editors (Francesco Puma and Hon Chi Suen) for the series "Surgical Management of Chest Wall Tumors" published in Current Challenges in Thoracic Surgery. The article has undergone external peer review.

Reporting Checklist: The author has completed the Narrative Review reporting checklist. Available at https://ccts. amegroups.com/article/view/10.21037/ccts-2019-cwt-09/rc

Conflicts of Interest: The author has completed the ICMJE uniform disclosure form (available at https://ccts.amegroups. com/article/view/10.21037/ccts-2019-cwt-09/coif). The series "Surgical Management of Chest Wall Tumors" was commissioned by the editorial office without any funding or sponsorship. ML serves as an unpaid Associate Editor of
Current Challenges in Thoracic Surgery from March 2019 to March 2021.The author has no other conflicts of interest to declare.

Ethical Statement: The author is accountable for all aspects of the work in ensuring that questions related to the accuracy or integrity of any part of the work are appropriately investigated and resolved.

Open Access Statement: This is an Open Access article distributed in accordance with the Creative Commons Attribution-NonCommercial-NoDerivs 4.0 International License (CC BY-NC-ND 4.0), which permits the noncommercial replication and distribution of the article with the strict proviso that no changes or edits are made and the original work is properly cited (including links to both the formal publication through the relevant DOI and the license). See: https://creativecommons.org/licenses/by-nc-nd/4.0/.

\section{References}

1. Goldstraw P, Chansky K, Crowley J, et al. The IASLC lung cancer staging project: proposals for revision of the TNM stage groupings in the forthcoming (eighth) edition of the TNM classification for lung cancer. J Thorac Oncol 2016;11:39-51.

2. Piehler JM, Pairolero PC, Weiland LH, et al. Bronchogenic carcinoma with chest wall invasion: factors affecting survival following en bloc resection. Ann Thorac Surg 1982;34:684-91.

3. McCaughan BC, Martini N, Bains MS, et al. Chest wall invasion in carcinoma of the lung. Therapeutic and prognostic implications. J Thorac Cardiovasc Surg 1985;89:836-41.

4. Magdeleinat P, Alifano M, Benbrahem C, et al. Surgical treatment of lung cancer invading the chest wall: results and prognostic factors. Ann Thorac Surg 2001;71:1094-9.

5. Shaw RR, Paulson DL, Kee JL. Treatment of superior sulcus tumor by irradiation followed by resection. Ann Surg 1961;154:29-40.

6. Wright CD, Moncure AC, Shepard JA, et al. Superior sulcus lung tumors. Results of combined treatment (irradiation and radical resection). J Thorac Cardiovasc Surg 1987;94:69-74.

7. Attar S, Krasna MJ, Sonett JR, et al. Superior sulcus (Pancoast) tumor: experience with 105 patients. Ann Thorac Surg 1998;66:193-8. 
8. Rusch VW, Parekh KR, Leon L, et al. Factors determining outcome after surgical resection of T3 and T4 lung cancers of the superior sulcus. J Thorac Cardiovasc Surg 2000;119:1147-53.

9. Coleman FP. Primary carcinoma of the lung, with invasion of the ribs: pneumonectomy and simultaneous block resection of the chest wall. Ann Surg 1947;126:156-68.

10. Downey RJ, Martini N, Rusch VW, et al. Extent of chest wall invasion and survival in patients with lung cancer. Ann Thorac Surg 1999;68:188-93.

11. Ginsberg RJ, Martini N, Zaman M, et al. Influence of surgical resection and brachytherapy in the management of superior sulcus tumor. Ann Thorac Surg 1994;57:1440-5.

12. Attar S, Miller JE, Satterfield J, et al. Pancoast's tumor: irradiation or surgery? Ann Thorac Surg 1979;28:578-86.

13. Doddoli C, D'Journo B, Le Pimpec-Barthes F, et al. Lung cancer invading the chest wall: a plea for en-bloc resection but the need for new treatment strategies. Ann Thorac Surg 2005;80:2032-40.

14. Dartevelle PG, Chapelier AR, Macchiarini P, et al. Anterior transcervical-thoracic approach for radical resection of lung tumors invading the thoracic inlet. J Thorac Cardiovasc Surg 1993;105:1025-34.

15. Rusch VW, Giroux DJ, Kraut MJ, et al. Induction chemoradiation and surgical resection for superior sulcus non-small-cell lung carcinomas: long-term results of Southwest Oncology Group Trial 9416 (Intergroup Trial 0160). J Clin Oncol 2007;25:313-8.

16. Kunitoh H, Kato H, Tsuboi M, et al. Phase II trial of preoperative chemoradiotherapy followed by surgical resection in patients with superior sulcus non-small-cell lung cancers: report of Japan Clinical Oncology Group trial 9806. J Clin Oncol 2008;26:644-9.

17. Collaud S, Waddell TK, Yasufuku K, et al. Long-term outcome after en bloc resection of non-small-cell lung cancer invading the pulmonary sulcus and spine. J Thorac Oncol 2013;8:1538-44.

18. Kawaguchi K, Yokoi K, Niwa H, et al. A prospective, multi-institutional phase II study of induction chemoradiotherapy followed by surgery in patients with non-small cell lung cancer involving the chest wall (CJLSG0801). Lung Cancer 2017;104:79-84.

19. Facciolo F, Cardillo G, Lopergolo M, et al. Chest wall invasion in non-small cell lung carcinoma: a rationale for en bloc resection. J Thorac Cardiovasc Surg 2001;121:649-56.

20. Akata S, Kajiwara N, Park J, et al. Evaluation of chest wall invasion by lung cancer using respiratory dynamic MRI. J Med Imaging Radiat Oncol 2008;52:36-9.
21. Berthet JP, Canaud L, D'Annoville T, et al. Titanium plates and Dualmesh: a modern combination for reconstructing very large chest wall defects. Ann Thorac Surg 2011;91:1709-16.

22. Girotti P, Leo F, Bravi F, et al. The "rib-like" technique for surgical treatment of sternal tumors: lessons learned from 101 consecutive cases. Ann Thorac Surg 2011;92:1208-15; discussion 1215-6.

23. Marulli G, Hamad AM, Cogliati E, et al. Allograft sternochondral replacement after resection of large sternal chondrosarcoma. J Thorac Cardiovasc Surg 2010;139:e69-70.

24. Suganuma N, Wada N, Arai H, et al. Chest wall resection and reconstruction using titanium micromesh covered with Marlex mesh for metastatic follicular thyroid carcinoma: a case report. J Med Case Rep 2009;3:7259.

25. Wang B, Song M, Tang J, et al. Sternoclavicular joint and sternal reconstruction with 3-dimensional carbonfiber prosthesis. Semin Thorac Cardiovasc Surg 2020;32:171-3.

26. Albertucci M, DeMeester TR, Rothberg M, et al. Surgery and the management of peripheral lung tumors adherent to the parietal pleura. J Thorac Cardiovasc Surg 1992;103:8-12; discussion 12-3.

27. Patterson GA, Ilves R, Ginsberg RJ, et al. The value of adjuvant radiotherapy in pulmonary and chest wall resection for bronchogenic carcinoma. Ann Thorac Surg 1982;34:692-7.

28. Kawaguchi K, Yokoi K, Niwa H, et al. Trimodality therapy for lung cancer with chest wall invasion: initial results of a phase II study. Ann Thorac Surg 2014;98:1184-91.

29. Ettinger DS, Wood DE, Aggarwal C, et al. NCCN guidelines insights: non-small cell lung cancer, version 1.2020. J Natl Compr Canc Netw 2019;17:1464-72.

30. Chapelier A, Fadel E, Macchiarini P, et al. Factors affecting long-term survival after en-bloc resection of lung cancer invading the chest wall. Eur J Cardiothorac Surg 2000;18:513-8.

31. Deslauriers J, Tronc F, Fortin D. Management of tumors involving the chest wall including pancoast tumors and tumors invading the spine. Thorac Surg Clin 2013;23:313-25.

32. Jones GD, Caso R, No JS, et al. Prognostic factors following complete resection of non-superior sulcus lung cancer invading the chest wall. Eur J Cardiothorac Surg 2020;58:78-85.

33. Voltolini L, Rapicetta C, Luzzi L, et al. Lung cancer 
with chest wall involvement: predictive factors of longterm survival after surgical resection. Lung Cancer 2006;52:359-64.

doi: 10.21037/ccts-2019-cwt-09

Cite this article as: Lanuti $M$. A narrative review of surgical management of lung cancer involving the chest wall: oncologic results. Curr Chall Thorac Surg 2021;3:17.
34. Casillas M, Paris F, Tarrazona V, et al. Surgical treatment of lung carcinoma involving the chest wall. Eur J Cardiothorac Surg 1989;3:425-9. 